\title{
Effect of chitosan-beeswax edible coatings on the shelf-life of Sapodilla (Achras zapota) fruit
}

\begin{abstract}
The aim of this study was to investigate the effect of chitosan and beeswax as edible coatings on the shelf-life of sapodilla (Achras zapota). The coating formulations used were chitosan only $(C)$, chitosan with $10 \%$ beeswax $(C+10 B)$ and chitosan with $20 \%$ beeswax $(C+20 B)$. Sapodilla without any coating $(\mathrm{WC})$ was used as a control. The coating formulations, $\mathrm{C}+10 \mathrm{~B}$ and $\mathrm{C}+20 \mathrm{~B}$ had shown to be the best in reducing the senescence of sapodilla as they slowed down the weight loss and breakdown of soluble solids in the fruit, while retaining the firmness and skin colour. Microbial populations of $\mathrm{C}+10 \mathrm{~B}$ and $\mathrm{C}+20 \mathrm{~B}$ were also below permissible microbial food limit ( $5 \log \mathrm{CFU}$ $\mathrm{g}-1$ ) over the period of 17 days if compared to $\mathrm{WC}$ and $\mathrm{C}$, which exceeded the limit. However, $\mathrm{C}+10 \mathrm{~B}$ started to shrivel towards the end of storage. In conclusion, $\mathrm{C}+20 \mathrm{~B}$ showed the best edible coating formulation in extending the shelf-life of sapodilla.
\end{abstract}

Keyword: Chitosan; Beeswax; Edible coating; Shelf-life; Sapodilla (Achras zapota) 